Tourism in Analysis

DOI: http://dx.doi.org/10.11606/issn.1984-4867.v27i3p543-567

\title{
Hospitalidade e lazer para pacientes-viajantes e seus acompanhantes na região do Hospital de Câncer de Barretos, SP, Brasil
}

\section{Hospitality and leisure for traveler patients and their companions in the area of the Cancer Hospital in Barretos, SP, Brazil}

Hospitalidad y prácticas de ocio para los pacientes-viajeros y sus acom-
pañantes en la región del Hospital de Cáncer de Barretos, SP, Brasil

Aliane Sousa Silva ${ }^{1}$

Ricardo Lanzarini ${ }^{2}$

\begin{abstract}
Resumo
Esta pesquisa abordou as relações humanas e bem-estar de pacientes-viajantes que realizam tratamento oncológico no Hospital de Câncer de Barretos, SP, Brasil - bem como de seus acompanhantes -, com o objetivo de identificar as práticas de lazer disponíveis e/ou realizadas no entorno do hospital, local onde se concentra a maioria dos meios de hospedagem utilizados por pacientes provenientes de outras regiões do Brasil e do exterior. Mais além, procurou-se conhecer o atendimento hoteleiro a fim de identificar a percepção desse público frente a hospitalidade local. O trabalho foi realizado de maio a novembro de 2015, por meio do método fenomenológico de caráter descritivo, com a aplicação de entrevistas semiestruturadas realizadas com pacientes-viajantes em tratamento no Hospital de Câncer, seus acompanhantes e empresários do setor hoteleiro. Dentre os resultados, constatou-se que essas pessoas sentem-se bem acolhidas em Barretos e, apesar do contexto da doença e de suas condições físicas e/ou emocionais, elas atestaram a necessidade de mais espaços de lazer na cidade, como praças e telões de cinema, bem como algumas atividades que lhes permitissem o recreio, de modo a tornar mais agradável o tempo livre durante o tratamento oncológico, além de possibilitar a dinamização da economia do turismo local.

Palavras-chave: Turismo; Lazer; Hospitalidade; Paciente; Hospital de Câncer de Barretos.
\end{abstract}

\footnotetext{
1 Graduada em Gestão de Turismo pelo Instituto Federal de Educação, Ciência e Tecnologia de São Paulo Campus Barretos (IFSP). Técnica em Enfermagem pelo Centro de Formação de Recursos Humanos para SUS - CEFORSUS. Barretos, São Paulo, Brasil. E-mail: lia.brito@hotmail.com

2 Pós-doutor em Lazer e Turismo pela Universidade de São Paulo (USP). Doutor em Ciências Humanas pela Universidade Federal de Santa Catarina (UFSC). Docente do curso de Tecnologia em Gestão de Turismo do Instituto Federal de São Paulo (IFSP). Professor Colaborador no Programa de Pós-Graduação em Gestão de Turismo do Instituto Federal de Sergipe (IFS). Orientador Pleno do Programa de Pós-Graduação em Estudos Culturais da Escola de Artes, Ciências e Humanidades da Universidade de São Paulo (EACH/USP). São Paulo, São Paulo, Brasil. E-mail: ricardolanzarini@gmail.com
} 


\begin{abstract}
This research analyzed traveler patients' human relations and well-being during cancer treatment in the Cancer Hospital in Barretos, SP, Brazil - as well as their companions -, aiming to identify the leisure activities available and/or performed in the hospital surroundings, where most of the accommodations used by the patients from other regions of Brazil and abroad are located. Furthermore, the hotel services were studied to identify the public's perception concerning the local hospitality. The study was conducted from May to November of 2015, using a descriptive phenomenological research approach, it were applied semi-structured interviews with the traveler patients under treatment in the Cancer Hospital, their companions and hospitality entrepreneurs. The results showed that these people felt welcomed in Barretos and, although struggling with the disease and its physical and/or emotional conditions, they confirmed the need for an increase in public leisure areas in the city, like squares and movie screens, as well as some activities that enable them to have a break for leisure, in order to make more pleasant their free time during cancer treatment, besides allowing the stimulation of the local tourism economy.
\end{abstract}

Keywords: Tourism; Leisure; Hospitality; Patients; Cancer Hospital in Barretos.

\title{
Resumen
}

En esta investigación se abordaron las relaciones humanas de proximidad y bienestar de pacientes-viajeros que realizan tratamiento para el cáncer en el Hospital del Cáncer de Barretos, SP, Brasil, así como sus cuidadores, con el fin de identificar las actividades disponibles de ocio y/o realizadas en ambiente hospitalario, donde se concentran la mayoría de las instalaciones del alojamiento utilizadas por pacientes de otras regiones de Brasil y del extranjero. Además, trató de conocer los servicios del hotel para identificar la percepción de este público acerca de la hospitalidad local. El estudio se realizó entre mayo y noviembre de 2015, a través del método fenomenológico de carácter descriptivo, con la aplicación de entrevistas semiestructuradas con pacientes-viajeros bajo tratamiento en el Hospital del Cáncer, sus acompañantes y los empresarios de la industria hotelera. Entre los resultados, parece que estas personas se sienten bienvenidas en Barretos, a pesar del contexto de la enfermedad y de sus condiciones físicas y emocionales, y dan fe de la necesidad de más espacios de ocio públicos en la ciudad, tales como plazas y pantallas de cine, así como algunas actividades que les permitan hacer más agradable el tiempo libre durante el tratamiento del cáncer, además de permitir la revitalización de la economía turística local.

Palabras clave: Turismo; Ocio; Hostelería; Paciente; Hospital del Cáncer de Barretos.

\section{Primeiras considerações}

Turismo e saúde são temas transversais que aparecem em diversos contextos das viagens e da produção do fenômeno turístico. As apropriações sociais da ideia de turismo enquanto 
atividade de lazer, que serve para promover o descanso e o relaxamento, advêm do conceito de qualidade de vida, saúde e bem-estar. Autores como Krippendorf (2009), que associam a atividade turística a uma válvula de escape das tensões diárias, embora não fale precisamente do conceito de saúde, remete à necessidade que as pessoas criam de fugir do dia a dia para estar bem, fato que impõe ao turismo a característica de ser considerado como artigo de primeira necessidade na sociedade moderna.

No entanto, o bem-estar promovido pela viagem pode ir bem mais além de questões psicológicas e/ou de status social. Em muitos casos, o turismo atende à busca por tratamentos médico-hospitalares, por exemplo, uma vez que contempla o deslocamento de pessoas para diversas regiões do Brasil e do mundo. Tais pessoas passam muitos dias, meses ou anos em tratamento médico, utilizando toda a infraestrutura que o turismo oferece, como equipamentos de hospedagem, agenciamento, alimentação, lazer e entretenimento.

No caso do Brasil, o câncer é uma das doenças que mais mata e, consequentemente, das que mais movimenta o fluxo de pessoas em busca de tratamento. De acordo com a Revista Exame (BRETAS, 2015), em dez anos, o câncer matou mais de 1,5 milhão de brasileiros e, conforme o Ministério da Saúde (Brasil, 2015), a estimativa no biênio 2016-2017, aponta a ocorrência de cerca de 600 mil novos casos de câncer no Brasil.

É nesse cenário que o município de Barretos, no estado de São Paulo, ganha expressivo destaque em virtude da Fundação Pio XII - Hospital de Câncer (HC). Além disso, no que tange ao setor turístico, Barretos é conhecido internacionalmente por sediar a maior Festa do Peão de Boiadeiro do Brasil. O evento tem grande importância para a economia local, pois permite o crescimento de setores como alimentação, hospedagem e a produção de artigos country, com enorme efeito multiplicador em termos de geração de renda e emprego, fato que, juntamente com o fluxo de pacientes e acompanhantes do HC, tem consolidado o mercado turístico no município.

Com objetivo de identificar e analisar hospitalidade e lazer na região do HC, esta pesquisa foi realizada entre maio e novembro de 2015 em Barretos/SP, com acompanhantes e pacientes-viajantes, a fim de identificar que tipo de equipamento de lazer existe nos espaços ao redor do HC, analisar a hospitalidade das pousadas e hotéis, a partir do olhar dos hóspedes, além de compreender a importância do lazer como prática social que beneficia/estimula o sentimento de acolhida dos pacientes-viajantes e acompanhantes no entorno do HC. 
Atualmente, com mais de 250 médicos e mais de 2500 funcionários, o $\mathrm{HC}$ atende pacientes de todo o país e do exterior. Está provido com os mais sofisticados equipamentos usados para prevenção, diagnóstico e tratamento oncológico, contando com um alojamento especial para crianças em tratamento. Diariamente, são servidas seis mil refeições e mais de 2 mil quilos de roupas são lavadas (ACIB, [s.d.]).

Em muitos casos de câncer, os tratamentos periódicos são quimioterapia e radioterapia, fazendo que os pacientes e seus acompanhantes permaneçam vários meses em Barretos - especialmente aqueles que vêm de regiões distantes -, mesmo que não estejam internados no HC. Logo, no dia a dia dessas pessoas há um tempo livre que costuma ser maior que o convencional, dado ao desligamento de seus cotidianos, trabalho e obrigações familiares. Nesse contexto, é comum encontrar os pacientes não internos e seus acompanhantes circulando nas proximidades do $\mathrm{HC}$ em busca de atividades e equipamentos de lazer e entretenimento como forma de distração e/ou ocupação.

Sabe-se que, com os notáveis avanços científicos que integram o corpo e a mente no processo de recuperação, a relação entre saúde e doença evoluiu nas últimas décadas, por isso, a qualidade de vida, que está associada à atividade física e ao lazer cotidiano pode trazer possíveis benefícios ao paciente. Para Forattini (1991), reconhecem-se socialmente dois tipos de necessidades específicas ligadas ao conceito de qualidade de vida: as concretas - de ordem geral, como moradia e alimentação; e as abstratas - de aspecto mais particular, como a autoestima. Durante a estadia em Barretos, os pacientes do HC buscam qualidade de vida, no meio urbano, tal qual um residente, distanciando-se do contexto do turista convencional. Com relação à doença abordada nesta pesquisa, pode-se afirmar que o câncer é uma doença que apresenta, na atualidade, alto índice de ocorrências no mundo todo, fato que gera insuficiência de hospitais especializados. No caso do Brasil, o retrato mais comum dos hospitais públicos apresenta poucos profissionais especializados e falta de estrutura adequada.

Câncer é o nome genérico para um grupo de mais de duzentas doenças. Embora existam muitos tipos de câncer, todos começam devido ao crescimento anormal e fora de controle das células - conhecido como neoplasia. Essa doença é estudada e tratada pelo ramo da medicina conhecido como Oncologia. De acordo com a Secretaria de Estado da Saúde de São Paulo, Barretos tem o melhor hospital conveniado ao Sistema Único de Saúde (SUS) para 
tratamento do câncer ${ }^{3}$ no país. Diante dos serviços prestados aos pacientes de todo o país, o Ministério da Saúde reconhece que o HC é o melhor prestador de serviços entre os 6530 hospitais públicos e particulares avaliados e lhe confere o prêmio "Qualidade Hospitalar 2000" (ACIB, [s.d.]).

Em virtude da condição da doença - somada ao sofrimento e angústia diária desses pacientes e acompanhantes, potencializada pelo tempo ocioso -, esses viajantes estão inseridos em uma condição alheia ao turismo, que é socialmente visto como viagens de lazer e/ou férias, relacionadas à ideia de prazer. Para Santoro (2007), o prazer está associado ao desejo de algo que não se tem, sendo sua realização temporária e constantemente necessária; fato esse que poderia amenizar a condição de doença e dor que fomentou a viagem. Por esse motivo, e em solidariedade à condição humana apresentada pelos entrevistados, optou-se por identificá-los como "pacientes-viajantes" e seus "acompanhantes" ao invés de "turistas".

De qualquer forma, durante a estadia na cidade, esses viajantes se utilizam de serviços de alimentação e hospedagem nas imediações do hospital por vários dias consecutivos e alternados ao longo de anos em tratamento, o que lhes oportuniza também utilizar equipamentos de lazer para aliviar o sofrimento e melhorar a qualidade de vida, fato que gera lucro e circulação de bens e serviços, configurando um mercado promissor para o setor turístico local. Outro fator importante se refere à hospitalidade local frente a esse público - formado por pacientes e seus acompanhantes, em sua maioria, familiares do paciente -, que, além de possuir características específicas, encontra-se emocionalmente abalado pela doença. Assim, esta pesquisa buscou compreender, por meio de entrevistas, se os hotéis e pousadas no entorno do HC, além da acomodação e infraestrutura, oferecem hospitalidade humanizada, que possibilite tornar a estadia mais acolhedora e tranquila, a fim de melhorar a qualidade de vida durante a hospedagem desses clientes.

Durante o processo de tratamento de câncer, o paciente - e, consequentemente, seus acompanhantes - passa por estágios de internação ou por atendimento ambulatorial, sendo identificado como não interno. No entanto, é necessário que ele fique algumas horas no HC para que seja submetido ao tratamento de radioterapia ou quimioterapia, sendo, depois, liberado para retornar ao seu respectivo meio de hospedagem, para pernoite ou para repouso entre as

3 Conforme dados da Associação Comercial de Barretos [s.d.], 98\% dos atendimentos do HC são viabilizados pelo Sistema Único de Saúde (SUS). 
Tourism in Analysis

sessões médicas. Também há os casos daqueles que, após a alta médica, precisam retornar a Barretos periodicamente para o controle da doença, situação que pode gerar vínculos sociais e/ou de afetividade entre o consumidor e os prestadores de serviços de hospedagem.

\section{Turismo local e saúde}

A discussão que envolve os conceitos de turismo e saúde - que parecem simples e de fácil compreensão -, traz em suas raízes desacordos teóricos e dilemas práticos quanto ao entendimento e reconhecimento - por parte do público consumidor de saúde nas viagens - sobre a condição de turistas.

Para Sancho (2001), a atividade turística compreende ações que as pessoas realizam durante suas viagens e estadias em lugares diferentes ao seu entorno habitual, por um período consecutivo inferior a um ano, com finalidade de lazer, negócios ou outros motivos, alimentando um mercado próprio.

O mercado turístico se baseia no eterno confronto entre a demanda, os consumidores, no caso, os turistas, os produtores ou vendedores de produtos e serviços turísticos, no caso, as empresas hoteleiras, as agências de viagem, as empresas organizadoras de eventos, as empresas que atuam na área de entretenimento, de transporte, gastronomia etc. (FERNANDES; COELHO, 2002, p. 69)

Para Barretto (2003, p. 13), contudo, é preciso diferenciar o turismo de outras formas de viagem que incluem obrigações, pois a atividade turística deve ser de livre escolha. Assim, há muitas viagens que não são turísticas, a exemplo das "viagens de negócios, viagens de estudo, viagens para visitar parentes em ocasiões especiais, como doença ou morte, podem ser, mais que um prazer, compromissos sociais".

A autora expõe a atividade turística como uma prática livre, sem qualquer compromisso, por isso, entendida como atividade de lazer. Essa conceituação vai ao encontro do perfil aqui pesquisado: há um comprometimento com a doença, compromissos com o tratamento do 
Tourism in Analysis

câncer, dor e sofrimento tanto de pacientes quanto de acompanhantes, que esperam ansiosamente - e também ociosamente - a cura como fim último da viagem.

Ao longo da história, o turismo tem possibilitado o acesso a lugares e equipamentos especializados em saúde, especialmente para a terceira idade. Conforme Godoi (2004), desde o final do século XVIII, muitas localidades passaram a ser procuradas pelos seus recursos hidrominerais, motivando a exploração de recursos naturais em benefício da saúde física e mental dos turistas.

Já no século XX, com a evolução da indústria farmacêutica, o turismo de saúde em estâncias hidrominerais teve um significativo declínio e o mercado turístico apontou como público potencial uma demanda de viajantes que buscam tratamentos médicos em clínicas especializadas, surgindo o turismo de saúde médico-hospitalar, que se trata de:

Deslocamentos motivados pela realização de tratamentos e exames diagnósticos por meio do acompanhamento de recursos humanos especializados e integrados em estruturas próprias, tendo como objetivo tanto a cura ou a amenização dos efeitos causados por diferentes patologias, como fins estéticos e terapêuticos. (BRASIL, 2010b, p. 19)

Contrária à ideia apresentada por Barretto (2003), o Ministério do Turismo (BRASIL, 2010b) aponta a saúde como um importante vetor de atração de turistas, incluindo todas as obrigações do tratamento médico-hospitalar. Para o Ministério, o que importa realmente é que esses turistas, mesmo em um contexto de sofrimento, sejam capazes de movimentar o mercado turístico, já que podem utilizar todos os recursos disponibilizados ao turista convencional. O Ministério ainda aponta quais são as características do turismo de saúde, a saber: (1) promoção da saúde, envolvendo ações sistemáticas e contínuas de educação para a mudança de comportamentos e prevenção de maus hábitos no estilo de vida; (2) manutenção da saúde, associada a situações e práticas que possibilitam o lazer, o descanso físico e mental e a diminuição dos níveis de estresse; (3) prevenção de doenças, que envolve tratamentos, promoção e manutenção da saúde; (4) cura de doenças, com tratamentos realizados com acompanhamento de equipes médicas ou recursos humanos especializados e integrados em estruturas próprias, para a cura ou a amenização dos efeitos causados por diferentes patologias. 
Nesse âmbito, aparecem dois tipos essenciais de turismo de saúde: (1) turismo de bem-estar, que consiste em "atividades turísticas motivadas pela busca da promoção e manutenção da saúde realizada por meio de tratamentos, que visam à diminuição dos níveis de estresse, além da aprendizagem e manutenção de uma vida saudável e equilibrada" (Idem, p. 18); e (2) turismo médico-hospitalar, que contemplam “deslocamentos motivados pela realização de tratamentos e exames diagnósticos com objetivo tanto de cura quanto de amenização dos efeitos causados por diferentes patologias, como fins estéticos e terapêuticos" (Idem, p. 19). A Associação de Turismo Médico (Medical Tourism Association - MTA), nos Estados Unidos, realizou uma pesquisa junto aos turistas médico-hospitalar americanos, no ano de 2009 , que revela que cerca de $80 \%$ dos pacientes de turismo de saúde viajam acompanhados, e 95\% dos pacientes dizem que seus acompanhantes fazem turismo durante os procedimentos médicos do paciente ${ }^{4}$. Com base nessa pesquisa, pode-se fazer alusão ao cenário de tratamento oncológico no $\mathrm{HC}$, o que nos leva a questionar, além da questão da hospitalidade local, como o setor turístico tem se estruturado para atender essas pessoas.

Os estudos e levantamentos a respeito do mercado turístico no município de Barretos ainda são incipientes, e seus atrativos - equipamentos e infraestrutura - estão, em sua maioria, em processo de estruturação. Segundo dados da Secretaria Municipal de Turismo de Barretos (SETUR), no ano de 2014, o município registrou em seus atrativos voltados ao lazer uma média de 135 mil turistas, mas ainda não há pesquisas que demonstrem o perfil do turista e quantos deles estão usufruindo dos espaços de lazer enquanto fazem ou acompanham tratamentos oncológicos.

De acordo com o Instituto Nacional de Câncer (BRASIL, 2015), o número de casos da doença por cem mil habitantes (taxa bruta) não é fixo porque as condições de saúde e do ambiente, bem como hábitos e atitudes, variam de acordo com a área geográfica. A região Sudeste, onde está localizado o município de Barretos, concentra a população de maior risco no país para diferentes tipos de câncer associados a melhores condições socioeconômicas, ao desenvolvimento e à urbanização. O câncer de próstata é o mais incidente entre homens e a taxa bruta calculada na região é de 70,4. No caso das mulheres, a incidência média é de 71,0 para câncer de mama 5 .

\footnotetext{
4 Fonte: Ministério do Turismo (2010b, p. 28).

5 Fonte: <http://bit.ly/1kMxfAh>. Acesso em: 10 nov. 2016.
} 
Barretos tem uma população estimada em torno de 120 mil habitantes (IBGE, 2016) e o HC faz, em média, 4.100 atendimentos por dia (HOSPITAL..., 2016), o que representa, em apenas um mês, um número maior que a população total do município. Considerando-se então a taxa bruta apresentada pelo INCA no Brasil, e a relação de atendimentos por câncer e o número de habitantes, é fácil visualizar o impacto que o HC gera no município pelo número de pacientes-viajantes que chega e permanece no local, o que certamente ultrapassa $80 \%$ dos casos atendidos. Somam-se ainda os acompanhantes desses pacientes, os quais permanecem em Barretos enquanto durar o tratamento de seus assistidos.

No caso dos pacientes-viajantes que vêm a Barretos para tratamento no $\mathrm{HC}$, os mesmos permanecem, em quase $100 \%$ dos casos, por um período superior a 24 horas e inferior a um ano e, dependendo do tempo de tratamento, há recorrência de vários anos no município para que seja feito acompanhamento dos estágios da doença e/ recuperação, configurando, para o Ministério do Turismo, uma atividade turística motivada pela saúde; e, para Barretto, uma viagem por obrigação, que pode, em um momento livre, incluir o turismo.

Do ponto de vista econômico, as pessoas que estão em tratamento no $\mathrm{HC}$ contribuem com a economia local ao utilizarem a infraestrutura turística e de apoio ao turismo: hotéis, meios de transportes, restaurantes, equipamentos de lazer e entretenimento, bem como o comércio local. Nesse sentido, para o setor turístico, o paciente-viajante é um turista como qualquer outro, pois mobiliza a economia local e usufrui toda a cadeia produtiva que possibilita seus deslocamentos e estadias.

Outra figura que também se faz presente no contexto do tratamento de câncer são os acompanhantes dos pacientes, que podem ser familiares, conhecidos e/ou assistentes sociais, uma vez que há recomendação/proibição médica no que se refere a viagens desacompanhadas devido à fragilidade do paciente oncológico. Logo, o acompanhante-viajante também contribui positivamente para o desenvolvimento do turismo de uma localidade, tendo em vista que, muitas vezes, eles procuram atividades turísticas para se ocuparem durante o tratamento médico do paciente que acompanham, uma vez que, normalmente, gozam de boas condições físicas e psíquicas para atividades de lazer e entretenimento, além de maior tempo livre.

Cabe destacar que há um senso comum de que turista é aquele que viaja em férias, por lazer. Logo, em momento algum foi possível dialogar com esses viajantes usando a condição de "turista" que, para eles, soava de forma ofensiva, dadas as circunstâncias médicas que 
motivaram a viagem, reconhecendo-se apenas como pacientes e acompanhantes. A esse fator, pode-se afirmar que Barretto (2003) estaria correta em sua análise de que a doença que causa o deslocamento causa também instabilidade emocional, o que não condiz com a condição de turista, gerando recusa a essa imagem.

\section{Hospitalidade, lazer e qualidade de vida}

A hospitalidade é tão antiga quanto a própria civilização. A palavra deriva de hospice, que indica asilo ou albergue; uma antiga palavra francesa que significa dar ajuda e/ou abrigo aos viajantes, conforme cita Walker (2002). Para Lashley e Morrison (2004), a hospitalidade se refere às pessoas hospitaleiras, aquelas que exercem o papel de anfitriãs e oferecem conforto e segurança ao seu hóspede.

Há dois tipos de anfitrião (TELFER, 1996): o bom hospitaleiro, que possui uma hospitalidade natural e procura oferecer conforto e bem-estar ao hóspede, auxiliando em questões que podem ultrapassar a esfera da hospedagem; e o bom hospedeiro aquele que hospeda com eficiência, cumprindo o que lhe cabe comercialmente. Lashley (2015, p. 72) salienta que "é possível identificar uma série de razões para se oferecer hospitalidade. De um lado, a hospitalidade é oferecida na expectativa da contrapartida do ganho pessoal, enquanto, de outro, a hospitalidade é ofertada meramente pelo prazer de dar prazer a outras pessoas".

A hospitalidade exerce um papel fundamental no bem-estar do viajante, especialmente em casos como das pessoas que se hospedam nas proximidades do HC para tratamento oncológico. Por conta da fragilidade emocional e, por vezes física, causada pela doença, o lugar que substitui suas casas é de vital importância em sua recuperação. O sentimento de acolhida e compreensão das limitações ocasionadas pelo tratamento é capaz de gerar conforto e segurança emocional, como se os pacientes estivessem em suas próprias casas. Nessa perspectiva, a hospitalidade oferecida para este público deve ser a do "bom hospitaleiro", que acolhe e procura solucionar pequenos problemas de seus hóspedes e está disposto a dividir o que tem em benefício dos hóspedes, independente de sua procedência, cultura e/ou classe social. É o "receber bem" que atende ao desejo de "ser bem recebido", oferecendo aos clientes um serviço diferenciado, com qualidade e capaz de gerar satisfação. 
Conforme Boff (2005, p. 19), “A virtude da hospitalidade é abertura de coração, a coragem de enfrentamentos e superarmos as diferenças, é acolher as pessoas assim como elas se apresentam, sem desconfiança e preconceitos". A hospitalidade, o hospitaleiro e o hóspede são interdependentes em relações sociais e comerciais complexas, pois aproximam pessoas, culturas e diferentes costumes, crenças e classes sociais, de modo que essas trocas são capazes de criar laços de afeto ou rejeição, dependendo das experiências estabelecidas. Por outro lado, é preciso considerar que as questões comerciais influenciam as cobranças e expectativas dos clientes: há um contrato que se mantém na prestação do serviço que pode desumanizar as relações da hospitalidade.

Outro importante fator que influencia na experiência e na (in)satisfação dos pacientes-viajantes e seus acompanhantes em Barretos se refere às práticas de lazer que possam ocupar o tempo ocioso durante o tratamento. Sobre tais práticas de lazer, Dumazedier (2008, p. 34) afirma que:

O lazer é um conjunto de ocupações às quais o indivíduo pode entregar-se de livre vontade, seja para repousar, seja para divertir-se, recrear-se e entreter-se, ou ainda, para desenvolver sua informação ou formação desinteressada, sua participação social voluntária ou sua livre capacidade criadora após livrar-se ou desembaraçar-se das obrigações profissionais, familiares e sociais.

Ao longo da história, o lazer enquanto prática social foi considerado de um tempo totalmente desnecessário a um tempo necessário para o desenvolvimento e evolução do ser humano. $\mathrm{Na}$ atualidade, com a valorização do acúmulo de riquezas provenientes do trabalho pelo sistema capitalista, o tempo de lazer é valorizado e ressignificado como um tempo necessário e estimulado como, por exemplo, as férias remuneradas e o consequente crescimento do turismo no mundo todo. Logo, o lazer se despontou como um grande negócio. Igualmente, é inegável sua importância para o bem-estar social e individual (físico e mental): desfrutar de momentos de repouso e tranquilidade traz benefícios para a alma e o corpo, conforme cita Marcelino (2008, p. 45-46):

O acesso ao lazer, como um dos direitos sociais promulgados pela Constituição Brasileira de 1988, implica, pois, a educação de cidadãos capazes de identificar e viver as oportunidades diversificadas e disponíveis nos tempos e espaços cotidianos, com condições de compreendê-las e ressignificá-las, consciente a sua importância em suas vidas e das contradições que limitam sua vivência plena. 
O lazer compreende uma atividade prazerosa, que deve fazer parte da vida cotidiana como forma de qualidade de vida. No caso estudado, é de fundamental importância que os acompanhantes e os pacientes não internos tenham ao seu dispor, ao considerar que possuem muito tempo livre, equipamentos e opções de lazer acessíveis, de modo a aliviar as tensões do tratamento médico e a ocupar o tempo livre na viagem de forma lúdica e prazerosa.

Autores como Melo e Alves Junior (2012, p. 32) acreditam que: “as atividades de lazer são observáveis no tempo livre das obrigações, sejam elas profissionais, religiosas, domésticas ou decorrentes das necessidades fisiológicas" e Camargo (1992) salienta que o lazer depende da escolha pessoal, da gratuidade, do prazer e do tempo livre das obrigações cotidianas. Camargo (1998) também conceitua tempo livre como tempo liberado das obrigações familiares, profissionais e escolares. Para Requixa (1980), por sua vez, é no tempo livre que se encontra o tempo de lazer, em que se pratica turismo, recreação ou outras atividades livres. Nesse contexto, o lazer atua como uma válvula de escape das tensões cotidianas tanto para os pacientes-viajantes quanto para seus acompanhantes, e pode ser encarado como uma forma de auxiliar no tratamento oncológico. Somadas ao lazer estão práticas mais ligadas ao entretenimento (atividades pagas) e ao turismo, constituindo um bom negócio para o mercado local, que tem um público potencial ocioso na cidade de Barretos. Conforme Lohmann e Panosso Netto (2008, p. 79), “o entretenimento pode ser usado como algo positivo que traz algum tipo de satisfação e enriquecimento cultural ou mental". Contudo, no senso comum, lazer e entretenimento possuem praticamente o mesmo sentido ligado ao tempo livre e são associados a atividades prazerosas, identificados apenas como lazer, tal qual acontece com o "turista", que viajaria essencialmente por lazer, afastando-se do contexto hospitalar motivador da viagem.

Associar lazer à qualidade de vida no tratamento oncológico é um recurso que tem sido recomendado aos pacientes como forma de auxiliar no bem-estar geral e melhorar seus quadros clínicos, de modo que vários hospitais têm desenvolvido trabalhos relacionados ao lazer, como o Hospital Regional do Vale do Paraíba, em Taubaté/SP, que oferece, semanalmente, um grupo de coral voluntário para entretenimento dos pacientes; e o próprio HC, em Barretos/SP, que oferece cursos de trabalhos manuais, sala de jogos para pacientes e acompanhantes que permanecem hospedados na Casa Assistencial Santa Madre Paulina, local mantido pelo HC por meio de doações e trabalhos voluntários. Assim, o lazer tem um papel fundamental nas vidas dos pacientes-viajantes e de seus acompanhantes durante suas estadias em Barretos, 
promovendo o bem-estar físico e mental de todos, além de gerar renda e trabalho no município pela prestação de serviços específicos ligados ao setor de entretenimento e turismo.

Para compreender as práticas de lazer como parte da qualidade de vida ou, no caso aqui estudado, de temporada de hospedagem foram identificados os equipamentos de lazer no entorno do $\mathrm{HC}$, como elementos de utilidade gratuita ou como entretenimento para o desenvolvimento pessoal dos pacientes-viajantes e seus acompanhantes. De acordo com a Organização Mundial de Saúde (OMS), qualidade de vida é a percepção do indivíduo de sua inserção na vida no contexto da cultura e sistemas de valores nos quais ele vive e em relação aos seus objetivos, padrões e preocupações. No que se refere ao caso médico, Minayo, Hartz e Buss (2000, p. 8) salientam que a área médica utiliza o termo qualidade de vida "dentro do referencial da clínica, para designar o movimento em que, a partir de situações de lesões físicas ou biológicas, se oferecem indicações técnicas de melhorias nas condições de vida dos enfermos"; fato que pode ocorrer com práticas de lazer e entretenimento durante o tempo livre. No tempo livre, pode ocorrer lazer por atividades de repouso, jogos, recreação, valorização da sociabilidade, expressão e movimento para se livrar das obrigações, pressões psicológicas e desgastes, bem como o entretenimento com a visitação a pontos turísticos, cinemas, teatros, museus, entre outros. Marcelino (2008, p. 187) destaca que "qualidade de vida significa usufruir de uma vida boa. [...] Está ligado a viver bem, a ser feliz, a conseguir realizar o algo mais, a ir à frente, a transcender". O tempo livre bem aproveitado com geração de prazer e satisfação pessoal serve para recompor as energias e aliviar as tensões comuns do dia a dia, além da recuperação quanto ao sentimento de insegurança e de preocupação com a doença.

\section{Considerações metodológicas}

A pesquisa foi realizada entre os meses de maio e novembro de 2015, utilizando-se o método fenomenológico de caráter descritivo para a análise de campo, que ocorreu no entorno do $\mathrm{HC}$ de Barretos/SP. Foi considerado um diâmetro de $2 \mathrm{~km}$, onde o HC é o ponto central. A região delimitada como entorno envolveu um total de 23 equipamentos de hospedagem, sendo que todos os locais eram devidamente legalizados ${ }^{6}$. Logo, o critério de seleção adotado para

\footnotetext{
${ }^{6}$ Fonte: Secretaria Municipal de Finanças do Departamento de Receitas (BARRETOS, 2015).
} 
viabilizar o empreendimento como adequado para ser objeto da pesquisa foi a localização (devendo ser próximo ao HC) e a legalidade do serviço, assim, excluindo-se hospedarias informais e casas de família.

Com relação à diferenciação técnica dos termos "hotel" e "pousada", cita-se que o Ministério do Turismo (2010a, p. 6-7) classifica hotel como o "estabelecimento com serviço de recepção, alojamento temporário, com ou sem alimentação, ofertados em unidades individuais e de uso exclusivo do hóspede, mediante cobrança de diária"; e pousada o "empreendimento horizontal, composto de no máximo 30 unidades habitacionais e 90 leitos, com serviços de recepção, alimentação e alojamento temporário, podendo ser em um prédio único com até três pavimentos, ou contar com chalés ou bangalôs". Entretanto, a diferença para os hóspedes se estabelece essencialmente pelo preço, que tende a ser menor nas pousadas, além do ambiente familiar, que permite que as pessoas possam se sentir à vontade, como se estivessem em casa - como também acontece mais facilmente em pequenas pousadas, onde todos acabam se conhecendo, fazendo amigos e usufruindo das áreas comuns -, diferentemente do que se costuma encontrar em hotéis com serviço padronizado.

Quanto ao método fenomenológico, Prodanov e Freitas (2013, p. 35) salientam que "a fenomenologia não se preocupa, pois, com algo desconhecido que se encontre atrás do fenômeno; só visa o dado, sem querer decidir se esse dado é uma realidade ou uma aparência”, visto que:

O método fenomenológico limita-se aos aspectos essenciais e intrínsecos do fenômeno, sem lançar mão de deduções ou empirismos, buscando compreendê-lo por meio da intuição, visando apenas o dado, o fenômeno, não importando sua natureza real ou fictícia.

A fenomenologia refere-se ao "estudo dos fenômenos, daquilo que aparece à consciência, daquilo que é dado a partir de si mesmo [...] é também um amplo movimento científico e espiritual, extraordinariamente variado e ramificado, ainda hoje vivo" (LIMA, 2014, p. 10). Desse modo, possibilita a compreensão da experiência vivida pelas pessoas a partir de aspectos mais profundos como o humor, as sensações e emoções; é a experiência real vivida, seu significado e suas implicações (ANTHEA, 2015). Siani, Correa e Las Casas (2016, p. 201) entendem que a fenomenologia "se centra na experiência intuitiva capaz de apreender 
o mundo exterior, e [...] abala a crença mantida pelo homem comum de que os objetos existiam, independentemente de nós mesmos, nesse suposto mundo que nos seria estranho". Nesse contexto, a pesquisa descritiva é um dos principais recursos utilizados para descrever características de determinadas populações ou fenômenos (GIL, 2008). Tal qual se apresenta nesse texto, foi analisado e descrito o fenômeno migratório que ocorre em Barretos devido ao HC, a partir da experiência pessoal e das vivências cotidianas locais dos pacientes-viajantes e seus acompanhantes no período de tempo em que estão em Barretos.

Outra característica do método fenomenológico é seu caráter qualitativo que, de acordo com Dias (2011, p. 120),

permite o conhecimento das qualidades dos objetos ou fenômenos que se propõe estudar. Ela busca o próprio significado desses fenômenos, no meio em que eles naturalmente ocorrem. Portanto a pesquisa qualitativa esta mais próxima do fenômeno a ser estudado como forma de pesquisa direta, focada no público consumidor potencial.

s foram coletados via entrevistas semiestruturadas que, segundo Lüdke e André (1994, p. 34), "permite correções, esclarecimentos e adaptações que a torna sobremaneira eficaz na obtenção das informações desejadas". Já Mondada (1997, p. 59) argumenta que a entrevista consiste em "um acontecimento comunicativo no qual os interlocutores, incluindo o pesquisador, constroem coletivamente uma versão do mundo".

A partir de uma amostragem não probabilística intencional ${ }^{7}$, foram entrevistadas, por escolha aleatória, 92 pessoas no entorno do $\mathrm{HC}$, entre pacientes não internos e acompanhantes, que estavam ociosos nos meios de hospedagem, sentados em calçadas próximas ou mesmo nas portas de estabelecimentos comerciais à espera de atendimento; além disso, foram entrevistados quatro empresários do setor de hospedagem que possuem empreendimentos no perímetro delimitado, a fim de identificar como eles veem e se relacionam com seus clientes a partir da noção de hospitalidade e doença.

Dessa forma, os pacientes-viajantes e os acompanhantes entrevistados eram abordados e questionados a respeito da possibilidade da entrevista, tendo como critério essencial a

\footnotetext{
7 Para Bussad (2011, p. 96), a amostragem intencional "não é uma amostragem representativa. [...]. Os resultados da amostragem servem muito mais para entender o problema do que para estender os resultados para alguma possível população".
} 
condição de viajantes, independentemente de gênero, raça ou condição social. Tão pouco se considerou questões quantitativas, pois, seguindo as ideias de Bussad (2011), a busca era pela compreensão do fenômeno sem critérios probabilísticos. Assim, foi entrevistado o maior número de pessoas possível na delimitação de tempo e espaço. O mesmo se repetiu quanto aos empresários, que foram escolhidos a partir da observação de campo, considerando indicações dos viajantes e a aceitação para a entrevista. Nessa perspectiva, os entrevistados foram devidamente esclarecidos da pesquisa científica, os objetivos, método e procedimentos adotados, bem como sobre a importância desta para a reflexão e melhoramento dos serviços turísticos locais. Foi-lhes garantido o direito a recusa ou a retirada do consentimento a qualquer momento e garantido o sigilo e a privacidade durante a pesquisa e na apresentação dos resultados, motivo pelo qual os entrevistados não foram identificados ${ }^{8}$.

\section{Resultados e discussões}

Do total de entrevistados, $62 \%$ eram do sexo feminino e $38 \%$ do sexo masculino. Desses, $64 \%$ estão casados, $23 \%$ solteiros, $9 \%$ divorciados e $4 \%$ viúvos, procedentes das seguintes regiões e estados: região Sudeste: São Paulo, Minas Gerais; Centro-Oeste: Mato Grosso do Sul, Mato Grosso e Goiás; região Norte: Tocantins, Pará, Amazonas, Rondônia, Roraima, Acre, Amapá; e região Nordeste: Bahia. Com relação à faixa etária, 28,2\% tinham entre 18 e 40 anos, 53,3\% entre 41 e 60 anos; e apenas 18,5\% mais de 60 anos.

Desse total, 54\% eram pacientes não internos do HC e 46\% acompanhantes de pacientes não internos. Ressalta-se que não era critério de seleção o acompanhante ter relação com os pacientes-viajantes, visto que as entrevistas foram aplicadas aleatoriamente. Logo, não foram entrevistados os acompanhantes de cada um dos pacientes e vice-versa, fato que justifica a diferença de porcentagem, bem como ressalta o critério de condição de permanência em Barretos mais que as relações pessoais, por se considerar que a opinião de um poderia influenciar a do outro, caso as entrevistas fossem realizadas simultaneamente.

\footnotetext{
8 A Resolução CNS 196/96 (versão 2012) da Comissão Nacional de Ética em Pesquisa esclarece, em seu Artigo $4^{\circ}$, que "o respeito devido à dignidade humana exige que toda pesquisa se processe com consentimento livre e esclarecido dos participantes, indivíduos ou grupos que, por si e/ou por seus representantes legais, manifestem a sua anuência à participação na pesquisa".
} 
Com relação à escolaridade dos entrevistados, 9\% concluíram o Ensino Superior; 35\% possuem o Ensino Médio completo; 3\% não concluíram o Ensino Médio; 27\% possuem o Ensino Fundamental completo; 23\% não concluíram o Ensino Fundamental; e 3\% não dispõem de qualquer instrução de ensino.

Em todos os casos, a permanência média em Barretos é de uma semana, de duas a três vezes ao ano, fato que os coloca na relação direta com o setor turístico local em virtude do uso de meios de transporte, hospedagem e equipamentos de alimentação, essencialmente.

Em relação aos meios de hospedagem utilizados, $80 \%$ preferem pousadas e apenas $20 \%$ se hospedam em hotéis. Sobre essa estimativa surgem duas fortes causas: a primeira relacionada ao custo de hospedagem, que no ano de 2015 girou em torno de R \$ 70,00 para pousadas e R\$ 120,00 para hotéis; e a segunda, porque nas pousadas há predomínio do ambiente familiar, de atendimento mais pessoal, geralmente oferecido pelo proprietário do estabelecimento, onde os clientes afirmam sentirem-se "em casa".

Sobre a hospitalidade oferecida pelos hotéis e pousadas, $65 \%$ consideram a hospitalidade boa, e 35\% responderam que a hospitalidade é ótima, o que os leva a se hospedarem sempre nos mesmos lugares, pois se sentem acolhidos como se estivessem na segurança de seus lares, desenvolvendo vínculos de afeto com os hospedeiros, especialmente nas pousadas - que apresentam um serviço menos padronizado e mais humanizado ao se envolverem com as questões físicas e emocionais de seus hóspedes em virtude do tratamento de câncer. Também, pode-se considerar como diferencial o fato de o fluxo de pessoas que se hospedam em pousadas ser sempre menor, o que permite maior liberdade e interação entre os hospedados e os hospedeiros, criando um clima de "grande família", na qual a maioria se encontra na mesma condição de sofrimento, fato que os aproxima em solidariedade.

O resultado da satisfação de hospitalidade, nesse caso, é altamente promissor e demonstra o envolvimento do trade turístico com as necessidades dos clientes, ultrapassando as fronteiras da boa prestação de serviço para uma condição humanizada de acolhimento, tal qual salienta Lashley (2015) sobre o prazer de proporcionar prazer às outras pessoas. Certamente, a condição do tratamento de saúde age a favor desse diferencial em Barretos, já habituado a receber visitantes em condições avessas ao turismo convencional. Mais além, identificou-se uma tendência dos hóspedes em valorizar esse atendimento humanizado em detrimento da prestação básica de serviços relacionados à infraestrutura: pequenos detalhes - como, por 
exemplo, uma roupa de cama que não foi devidamente higienizada - têm menos valor na avaliação da qualidade do equipamento para os hóspedes em tratamento ou seus acompanhantes do que teriam para os hóspedes que viajam a lazer ou trabalho, por exemplo. Assim, percebem-se como fatores determinantes da avaliação positiva dos hóspedes os laços afetivos, a atenção, o carinho e o cuidado com sua condição.

Para melhor compreender esse diferencial de hospitalidade, foram realizadas quatro entrevistas adjacentes com empresários do setor hoteleiro (dois proprietários de hotéis e dois de pousadas) no entorno do HC. Buscou-se, nessa fase, compreender a visão empresarial da hospitalidade e as relações que se constroem entre hóspedes e hospedeiros segundo a perspectiva daqueles que têm, no viajante, um negócio lucrativo.

Nos quatro depoimentos foi ressaltada a importância do atendimento humanizado que eles prestam por estarem lidando com hóspedes num ambiente que envolve doença e sofrimento, e que necessitam de acolhimento e auxílio especial - um serviço diferenciado pelo público em questão, que diverge bastante dos viajantes convencionais a trabalho ou a lazer. Por isso, priorizam um atendimento familiar, mais atento às questões emocionais dos hóspedes, havendo a necessidade de se saber conviver com a dor a as limitações que lhes impõe o tratamento oncológico. Ao se tratar da hospedagem (e da hospitalidade) como negócio, dois deles reforçam a importância de um meio de hospedagem que ajude as pessoas com câncer - além da renda que isso traz -, de modo que se sintam acolhidas e satisfeitas com a relação custo/benefício da hospedagem. Um empresário relatou que passou por um caso de doença na família anos atrás, fato que o obrigou a se mudar para a cidade, onde identificou a falta de hospedagens que atendessem a necessidade dos pacientes do $\mathrm{HC}$; fato que lhe mostrou uma oportunidade de trabalho e benfeitoria. Já o quarto proprietário, declarou que abriu o estabelecimento por motivos financeiros - já que viu naquela região grandes possibilidades de lucros -, mas trata seus hóspedes com muita dedicação e carinho para que se sintam "em casa".

Em todos os casos, os depoimentos vão ao encontro das falas dos hóspedes sobre o sentimento de acolhida, de uma hospitalidade que ultrapassa as relações do negócio empresarial e cria novas estruturas e dinâmicas sociais temporárias de bem-viver, que refletem em uma imagem positiva da cidade em relação a acolher seus visitantes; imagem essa que certamente ultrapassa as fronteiras do município e projeta positivamente Barretos no cenário turístico regional, nacional e internacional. 
Associar o lazer a esse cenário é um recurso promissor para o mercado local enquanto negócio e que tem sido amplamente recomendado aos pacientes do $\mathrm{HC}$ como forma de promover o bem-estar físico e, principalmente, emocional, de modo a contribuir com a melhora rápida de seus quadros clínicos. Além disso, o lazer e o entretenimento são fundamentais para preencher o tempo ocioso desses viajantes, de forma a somar satisfação com a hospitalidade e aperfeiçoar o mercado com a geração de empregos e renda, aproveitando-se de uma demanda ociosa já existente no município.

Ainda com relação à questão do tempo disponível na cidade, nos depoimentos dos pacientes-viajantes e seus acompanhantes, observou-se que $14 \%$ responderam que dispõem de até três horas livres para a prática de lazer e outros $77 \%$ atestam ter mais de três horas livres por dia. Sobre as atividades realizadas durante esse tempo livre, 50\% alegam fazerem nada, refletindo o ócio pela falta de boas opções de ocupação temporária ou desmotivação gerada pelo sofrimento; $32 \%$ compram no comércio local; $9 \%$ vão ao shopping (distante aproximadamente $4 \mathrm{~km}$ do $\mathrm{HC}$ ); 4\% ocupam seu tempo livre nas hospedagens, com hobbies como artesanato e jogos de azar; e 3\% assistem a programas de televisão ou cinema e costumam frequentar espaços religiosos em busca de conforto espiritual.

Esse panorama apresenta o grande número de viajantes ociosos que são encontrados em Barretos, dentre os quais a metade simplesmente não pratica qualquer atividade de lazer ou entretenimento. Igualmente, nenhum entrevistado cita realizar visitas aos atrativos turísticos locais mencionados em folhetos e sites especializados do município de Barretos, fato que demonstra a desarticulação do setor turístico frente a esse público.

Sobre o que eles acham dos equipamentos de lazer próximos ao $\mathrm{HC}, 73 \%$ alegam que desconhecem qualquer espaço ou atividade promovida pelo município; $20 \%$ acham que é bom, referindo-se ao comércio local, onde eles passam um tempo mais agradável e distante das pressões do tratamento médico; $5 \%$ consideram o lazer ótimo, mas não especificam espaços ou atividades - especialmente aqueles procedentes de cidades menos desenvolvidas comercialmente; e $2 \%$ consideram ruim, novamente sem qualquer especificação - em especial, aqueles procedentes de cidades mais desenvolvidas comercialmente. Há, declaradamente, um desconhecimento de causa sobre as questões do lazer e do entretenimento.

O senso de diversão, que relaciona esses dois conceitos, afasta a ligação com a condição de sofrimento e impõe aos entrevistados um descontentamento generalizado, evidenciado na 
maioria que alega desconhecer qualquer atividade do gênero no município. Outro importante ponto a ser destacado se refere à vivência da cidade: a maioria dos pacientes-viajantes e seus acompanhantes utiliza o serviço público de transporte no município, vivenciando com intensidade apenas a região do entorno do $\mathrm{HC}$, que essencialmente possui hospedagem, alimentação e residências; e, por isso, acabam usufruindo de outros pontos da cidade esporadicamente. Quando questionados sobre o que gostariam que fosse melhorado ou implementado como lazer e entretenimento - após prévio esclarecimento com exemplos -, as respostas indicam uma variedade de sugestões: $51 \%$ preferem uma praça com todo equipamento necessário para o lazer - quadra de esporte, pista de skate, equipamentos de ginástica, pista para caminhadas; $17 \%$ um parque urbano gratuito; $14 \%$ shows e cinema no entorno do HC; e 18\% não opinaram.

Prevalece a opção por atividades de lazer gratuitas e ligadas a espaços verdes, com equipamentos de descanso, como bancos, em áreas arborizadas, e atividades recreativas e de desporto, como mesas de jogos, quadras e pistas de caminhada. O entorno do HC é essencialmente urbano, sem espaços verdes ou áreas recreativas ou apropriadas a atividades físicas. Mesmo os equipamentos pagos são ausentes. O circuito turístico de bares, restaurantes e de entretenimento noturno é totalmente desligado da região, isolando grande parte dos viajantes que ali se encontram ociosos.

\section{Considerações finais}

A partir dessa pesquisa, constatou-se que os pacientes-viajantes do HC e seus acompanhantes, que se hospedam nas proximidades, consideram que os meios de hospedagem têm um diferencial no tratamento dos hóspedes, a partir de uma hospitalidade que vai além das questões comerciais, de modo a atender as necessidades psicológicas que lhes aproximam do sentimento de estarem seguros e em casa. Há uma prática especializada de acolhimento daquele que necessita de maior atenção pela fragilidade emocional em que se encontra, sem, contudo, perder o foco comercial quanto a prestação de serviço. Considera-se marcante a presença do "bom hospitaleiro", que nasce das relações sociais e das experiências pessoais de compaixão pelo sofrimento alheio; diferentemente da noção de hospitalidade proveniente de uma formação técnica, fato que é inexistente nesses empreendimentos de administração majoritariamente familiar. 
Muitos dos entrevistados aproveitam seu tempo livre dentro das hospedagens, com hobbies como o artesanato, essencialmente praticado por mulheres, e jogos de azar, pelos homens. Contudo, a maioria concorda que faltam equipamentos de lazer na cidade e que gostariam que houvesse praças e parques bem estruturados e seguros na região, assim como lugares que servissem refeições nos finais de semana - visto que praticamente todos os equipamentos de alimentação desse entorno não funcionam após o almoço de sábado.

Constatou-se, também, que esses viajantes, sejam pacientes ou acompanhantes, não se consideram turistas, dada a ligação do turismo com a ideia de férias ou de descanso/divertimento. Para eles, o motivo da viagem é somente o tratamento de saúde. Tal fato demonstra as diferenças entre a visão do cliente e a do empresário no setor turístico, já que, para o setor turístico local, os pacientes e seus acompanhantes são considerados turistas, trazem dinheiro e consomem serviços que qualquer viajante consome, caracterizando negócios promissores de hospedagem e alimentação no entorno do HC. Logo, o viajante, independente do motivo da viagem, é considerado como uma oportunidade de negócio.

A pesquisa foi realizada apenas na parte externa do hospital, não tendo, assim, qualquer vínculo com ele. Embora as pessoas tenham sido entrevistadas aleatoriamente, identificou-se um público de baixo ou médio poder aquisitivo, especialmente motivado pelo atendimento gratuito. Nesse sentido, o entorno do HC configura um ambiente de classe social menos favorecida, onde é possível encontrar comércios mais simples e hospedagens mais baratas, acentuando as diferenças sociais que segregam pessoas e aproximam semelhantes.

Considera-se, ainda, que os equipamentos de lazer são necessários para a distração desses pacientes e seus acompanhantes, de modo que possam ocupar o tempo livre e sentirem bem-estar durante a estadia em Barretos, mesmo no contexto árduo em que estão. A criação de espaços livres, que venham a melhorar inclusive a qualidade de vida dos moradores locais, é também uma oportunidade de negócio para o setor turístico e para o poder público; fato que, até o momento, é desconsiderado como possibilidade de agregar valor, desenvolver e diversificar o turismo do município.

O município tem uma situação privilegiada, já que possui uma demanda ociosa e que pode, por meio de incentivos fiscais, planejamento governamental e, também, de iniciativas 
privadas, aprimorar seus recursos turísticos, de lazer e de entretenimento. Contudo, espera-se que a expansão e a especialização dos serviços turísticos locais mantenham o contexto humanizado de acolher bem o viajante que busca, além do tratamento oncológico, afeto e segurança emocional.

Barretos é um município em que boa parte de sua hotelaria foi desenvolvida com base na demanda de viajantes em tratamento no HC. Certamente, a necessidade da demanda desenhou esse produto de forma singular, seja no seu atendimento pessoal, seja em sua estruturação em moldes familiares, abraçando a motivação da viagem - a doença - de forma não apenas humanizada, mas empreendedora, fato que resulta numa satisfação generalizada por parte dos consumidores.

Ainda em estágio de crescimento e organização, a atividade turística no município carece de muitos estudos de mercado, de serviços e de infraestrutura para a consolidação do setor, que apenas se destaca durante alguns eventos de grande e médio porte realizados anualmente. $\mathrm{O}$ fluxo de demanda ocasionado pelo HC encontra-se, ainda, desconectado das atratividades turísticas locais, não apenas com relação à falta de informação, mas também à falta de acesso a muitos dos equipamentos e espaços nos quais esses viajantes poderiam passar e ocupar boa parte do tempo livre.

Novos estudos e a interação entre poder público e privado, em parceria com associações e instituições de ensino, são urgentes para a organização dos espaços e das atividades que configuram um setor turístico comprometido com a comunidade local e com as necessidades do público, de modo a garantir a perpetuação da hospitalidade com o aprimoramento e expansão das atividades de lazer e entretenimento.

\section{Agradecimentos}

A realização deste trabalho é parte de um projeto piloto a respeito das práticas de hospitalidade e lazer no município de Barretos, fomentada pelo Grupo de Pesquisa CNPq: Sociedade, Cultura e Turismo: diálogos interdisciplinares (SoCulTur), com sede no Instituto Federal de Educação, Ciência e Tecnologia de São Paulo, campus Barretos. 


\section{Referências}

ACIB - ASSOCIAÇÃO COMERCIAL E INDUSTRIAL DE BARRETOS. Conheça Barretos: Festa do Peão. [s.d.]. Disponível em: <http://bit.ly/2gqJgBO>. Acesso em: 01 nov. 2015.

ANTHEA, W. A guide to phenomenological resource. Nursing Standard, v. 29, n. 34, p. 38-43, 2015.

BARRETOS (cidade). Prefeitura Municipal. Relatório de Turismo 2014. 2015. Disponível em: $<$ http://bit.ly/2guX6mL> Acesso: 27 abr. 2015.

BARRetTO, M. Manual de iniciação ao estudo do turismo. 13. ed. Campinas: Papirus, 2003. (Coleção Turismo).

BOFF, L. Virtudes para um outro mundo possível. Petrópolis: Vozes, 2005.

BRASIL. Ministério da Saúde. Comissão Nacional de Ética em Pesquisa. Resolução CNS 196/96 - versão 2012. Brasília, DF: Ministério da Saúde, 2012. Disponível em: <http://bit.ly/1AKjtdM>. Acesso em: 14 nov. 2016.

Ministério da Saúde. Instituto Nacional de Câncer José Alencar Gomes da Silva. Estimativa 2016: incidência de câncer no Brasil. Rio de Janeiro: INCA, 2015. Disponível em: <http://bit.ly/ 2dOy7Yz>. Acesso em: 13 nov. 2016.

. Ministério do Turismo. Sistema brasileiro de classificação de meios de hospedagem. 2010a. Disponível em: <http://bit.ly/1adtBZp>. Acesso em: 02 nov. 2016.

. Ministério do Turismo. Turismo de saúde: orientações básicas. Brasília, DF: Ministério do Turismo, 2010b.

BRETAS, V. Em 10 anos, câncer matou mais de 1,5 milhão de brasileiros. Revista Exame, 17 set. 2015. Disponível em: <http://abr.ai/2gxK8SS>. Acesso em: 13 nov. 2016.

BUSSAD, W. O. Introdução ao levantamento de dados (amostragem). In: DIAS, S. R. (Coord.). Pesquisa de mercado. São Paulo: Saraiva, 2011, p. 65-118.

CAMARGO, L. O. L. Educação para o lazer. São Paulo: Moderna, 1998.

O que é lazer. 3. ed. São Paulo: Brasiliense, 1992.

DENCKER, A. F. M. Métodos e técnicas de pesquisa em turismo. São Paulo: Futura, 1998.

DIAS, S. R. (Coord.). Pesquisa de mercado. São Paulo: Saraiva, 2011.

DUMAZEDIER, J. Lazer e cultura popular. São Paulo: Perspectiva, 2008. 
Tourism in Analysis

FERNANDES, I. P.; COELHO, M. F. Economia do turismo: teoria e prática. Rio de Janeiro: Campus, 2002.

FORATTINI, O. P. Qualidade de vida e meio urbano. A cidade de São Paulo, Brasil. Revista de Saúde Pública, v. 25, n. 2, p. 75-86, 1991.

FUNDAÇÃO PIO XII. Alojamentos. Disponível em: <http://bit.ly/2gGc1uM>. Acesso em: 21 nov. 2015.

GIL, A. C. Métodos e técnicas de pesquisa social. 6. ed. São Paulo: Atlas, 2008.

GODOI, A. F. Hotelaria hospitalar e humanização no atendimento em hospitais. São Paulo: Ícone, 2004.

HOSPITAL do Câncer de Barretos faz 4.100 atendimentos todos os dias. Jornal Hoje, 17 jun. 2016. Disponível em: $<\mathrm{http}: / /$ glo.bo/2fLQxIz> $>$. Acesso em: 13 nov. 2016.

IBGE - INSTITUTO BRASILEIRO DE GEOGRAFIA ESTATÍSTICA. Censo 2016: Barretos/SP. 2016. Disponível em: <http://bit.ly/2fRmPVX>. Acesso em: 13 nov. 2016.

KRIPPENDORF, J. Sociologia do Turismo. 3. ed. São Paulo: Aleph, 2009. (Série Turismo).

LAKATOS, E. M.; MARCONI, M. A. Fundamentos de metodologia cientifica. São Paulo: Atlas, 2010.

LASHLEY, C. Hospitalidade e hospitabilidade. Revista Hospitalidade, v. 12, p. 70-92, 2015. Número especial. Disponível em: <http://bit.ly/2fE8hdv>. Acesso em: 27 jan. 2016.

LASHLEY, C.; MORRISON, A. Em busca da hospitalidade: perspectivas para um mundo globalizado. Barueri: Manole, 2004.

LIMA, A. B. M. (Org.). Ensaios sobre fenomenologia: Husserl, Heidegger e Merleau-Ponty. Ilhéus: Editus, 2014.

LOHMANN, G.; PANOSSO NETTO, A. Teoria do turismo: conceitos, modelos e sistemas. São Paulo: Aleph, 2008. (Série Turismo).

LÜDKE, M.; ANDRÉ, M. Pesquisa em educação: abordagens qualitativas. São Paulo: Epu, 1994.

MARCELLINO, N. C. (Org.). Lazer e recreação: repertório de atividades por fases da vida. Campinas: Papirus, 2006.

. (Org.). Lazer e sociedade: múltiplas relações. Campinas: Alínea, 2008.

MELO, V. A.; ALVES JUNIOR, E. D. Introdução ao lazer. Barueri: Manole, 2012. 
MINAYO, M. C. S.; HARTZ, Z. M. A.; BUSS, P. M. Qualidade de vida e saúde: um debate necessário. Ciência e Saúde Coletiva, v. 5, n. 1, p. 7-18, 2000. Disponível em: <http://bit.ly/2glr6kO>. Acesso em: 15 jan. 2016.

MONDADA, L. A entrevista como acontecimento interacional: abordagem linguística e interacional. Rua, n. 3, p. 59-86, 1997.

PLENTZ, R. S. Dialética da hospitalidade: caminhos para a humanização. 2014. Dissertação (Mestrado em Turismo) - Universidade de Caxias do Sul, Caxias do Sul/RS: 2014. Disponível em: $<$ http://bit.ly/2bPUwTk>. Acesso em: 02 nov. 2015.

PRODANOV, C. C.; FREITAS, E. C. Metodologia do trabalho científico: métodos e técnicas da pesquisa e do trabalho acadêmico. 2. ed. Novo Hamburgo, 2013. Disponível em: $<$ http://bit.ly/2bPUwTk >. Acesso em: 01 nov. 2015.

REQUIXA, R. Sugestão de diretrizes para uma política nacional de lazer. São Paulo: Sesc, 1980.

SANCHO, A. (Org.). Introdução ao turismo: Organização Mundial do Turismo. São Paulo: Roca, 2001.

SANTORO, F. Arqueologia dos prazeres. São Paulo: Objetiva, 2007. (Coleção Filosófica).

SIANI, S. R.; CORREA, D. A.; LAS CASAS, A. L. Fenomenologia, método fenomenológico e pesquisa empírica: o instigante universo da construção do conhecimento esquadrinhada na experiência de vida. Revista de Administração da UNIMEP, v. 14, n. 1, p. 193-219, 2016. Disponível em: <http:// bit.ly/2gKVzGd>. Acesso em: 14 nov. 2016.

TELFER, E. Food for thought: philosophy and food. New York: Routledge, 1996.

TRIGO, L. G. G. et al. Aprendiz de lazer e turismo. São Paulo: Ipsis, 2007.

WALKER, J. R. Introdução à hospitalidade. Barueri: Manole, 2002.

Recebido em: 15/03/2016 (1 ${ }^{\mathrm{a}}$ versão) $06 / 11 / 2016$ ( $2^{\mathrm{a}}$ versão)

Aprovado em: 22/11/2016 